\title{
Dinâmica dos sistemas agroflorestais com as sinergias socioeconômicas e ambientais: caso dos cooperados nipo-paraenses da cooperativa agrícola mista de Tomé-Açu,
}

\section{Pará}

\author{
Dynamics of agroforestry systems with socioeconomic and environmental changes: case of nipo- \\ paraense cooperatives from the cooperativa agrícola mixed cooperative of Tomé-Açu, Para State \\ Dinámica de sistemas agroforestales con cambios socioeconómicos y ambientales: caso de las \\ cooperativas nipo-paraenses de la cooperativa agropecuaria mista de Tomé-Açu, Pará
}

Recebido: 23/09/2021 | Revisado: 03/10/2021 | Aceito: 04/01/2022 | Publicado: 05/01/2022

\author{
Marcus Victor Almeida Campos \\ ORCID: https://orcid.org/0000-0002-1579-5825 \\ Universidade do Estado do Pará, Brasil \\ E-mail: marcusvictor.campos@gmail.com \\ Alfredo Kingo Oyama Homma \\ ORCID: https://orcid.org/0000-0003-0330-9858 \\ Empresa Brasileira de Pesquisa Agropecuária, Brasil \\ E-mail: alfredo.homma@embrapa.br \\ Antônio José Elias Amorim de Menezes \\ ORCID: https://orcid.org/0000-0002-3294-5354 \\ Empresa Brasileira de Pesquisa Agropecuária, Brasil \\ E-mail: antonio.menezes@embrapa.br \\ Gisalda Carvalho Filgueiras \\ ORCID: https://orcid.org/0000-0002-4695-6505 \\ Universidade Federal do Pará, Brasil \\ E-mail: gisalda.filgueiras@gmail.com \\ Walmer Bruno Rocha Martins \\ ORCID: https://orcid.org/0000-0001-8795-1703 \\ Universidade do Estado do Pará, Brasil \\ E-mail: walmerbruno@gmail.com
}

\begin{abstract}
Resumo
O grande dilema na agricultura frente aos problemas socioambientais é alcançar a racionalização do dinâmico processo produtivo através da incorporação de novas tecnologias, redução dos custos de produção (mantendo níveis desejáveis de produtividade) e diminuição dos impactos ambientais, aliado a geração de maiores benefícios sociais. O presente estudo tem por objetivo principal avaliar a dinâmica dos sistemas agroflorestais dos cooperados descendentes de japoneses da Cooperativa Agrícola Mista de Tomé-Açu (CAMTA) no período de 1974 até 2020. Os dados de produção e valor da produção foram obtidos através da plataforma SIDRA e no site do Censo Agropecuário 2017. As espécies analisados no presente estudo são: açaízeiro, aceroleira, cacaueiro, cupuaçuzeiro, maracujazeiro, pimenteirado-reino e pitaya. Outro meio de coleta de dados foram os Relatórios Anuais da CAMTA, mais especificamente, avaliando o período de 1974 até o ano de 2020, a partir destes dados foi analisado o comportamento do percentual do valor de produção, ou seja, quanto em porcentagem cada espécies contribuiu para a renda total da cooperativa em um determinado ano. Para análise de dados foi utilizado o software Microsoft Office Excel 2019 para a elaboração de tabelas, e de gráficos de linha para melhor representarem o comportamento da porcentagem ao decorrer do tempo.
\end{abstract}

Palavras-chave: Desenvolvimento; Estratégias; Produtividade.

\begin{abstract}
The great dilemma in agriculture in the face of socio-environmental problems is to achieve the rationalization of the dynamic production process through the incorporation of new technologies, reduction of production costs (maintaining desirable levels of productivity) and reduction of environmental impacts, combined with the generation of greater social benefits. The main objective of this study is to evaluate the dynamics of the agroforestry systems of the mixed cooperative of Tomé-Açu in the period from 1974 to 2020 . The production data and production value were obtained through the SIDRA platform and on the Census of Agriculture 2017. The crops analyzed in the present study are açaí, acerola, cocoa, cupuaçuzeiro, passion fruit, black pepper and dragon fruit. Another means of data collection was the Annual Reports of the Cooperativa Agrícola Mista de Tomé-Açu, more specifically, evaluating the period from 1974 to 2020, based on these data, the behavior of the percentage of the production value was analyzed, in other
\end{abstract}


words, how much in percentage each specie contributed to the cooperative's total income in a given year. For data analysis, Microsoft Office Excel 2019 software was used for the preparation of tables. In addition, line graphs to better represent the behavior of percentage over time.

Keywords: Development; Strategies; Productivity.

\section{Resumen}

El gran dilema de la agricultura ante los problemas socioambientales es lograr la racionalización del proceso productivo dinámico mediante la incorporación de nuevas tecnologías, la reducción de los costos de producción (manteniendo niveles deseables de productividad) y la reducción de los impactos ambientales, combinados con la generación de mayores beneficios sociales. El presente estudio tiene como objetivo principal evaluar la dinámica de los sistemas agroforestales de la Cooperativa Agrícola Mista de Tomé-Açu en el período de 1974 a 2020. Los datos de producción y el valor de la producción se obtuvieron a través de la plataforma SIDRA y sobre el Censo Agropecuario 2017. Las especies analizados en este estudio son: açaí, acerola, cacao, cupuaçu, maracuyá, pimienta negra y pitaya. Otro medio de recolección de datos fueron los Informes Anuales de la Cooperativa Agrícola Mista de Tomé-Açu, más específicamente, evaluando el período de 1974 a 2020, a partir de estos datos se analizó el comportamiento del porcentaje del valor de la producción, es decir, cómo mucho en porcentaje cada especie contribuyó a los ingresos totales de la cooperativa en un año determinado. Para el análisis de datos se utilizó el software Microsoft Office Excel 2019 para la elaboración de tablas y gráficos de líneas para representar mejor el comportamiento de la porcentaje a lo largo del tiempo.

Palabras clave: Desarrollo; Estrategias; Productividad.

\section{Introdução}

O grande dilema na agricultura amazônica frente aos problemas socioambientais é alcançar a racionalização do dinâmico processo produtivo através da incorporação de novas tecnologias, redução dos custos de produção (mantendo níveis desejáveis de produtividade) e diminuição dos impactos ambientais, aliado a geração de maiores benefícios sociais (Kato et al., 2012). Os Sistemas Agroflorestais (SAFs) foram apontados como uma estratégia produtiva da recuperação ambiental, valorização dos conhecimentos tradicionais, diversificação produtiva e dos fatores sociais, econômicos e ecossistêmicos que o sistema de produção o abarca (Nascimento et al., 2019; Almeida, 2019).

A diversificação dos plantios surgiu em decorrência da disseminação da fusariose nas pimenteiras do reino (Piper nigrum L.) a partir de 1957 e da queda de preços decorrente da expansão desordenada dos plantios. A fusariose, ocasionada pelo fungo Fusarium solani f. sp. piperis, devastou os plantios a partir da década de 1970 (Homma, 2006; Tafner Jr., 2014).

Neste contexto, a demanda por alternativas de produção levou os imigrantes de japoneses e seus descendentes, estabelecidos no município de Tomé-Açu, Estado do Pará, a criar outras possibilidades de plantio, os sistemas consorciados (cultivos perenes e anuais), que originaram os SAFs (Homma, 1998; Homma, 2007; Barros 2009; Bolfe \& Batistella, 2011; Kato et al., 2012).

Os SAFs comumente encontrados nos municípios de Tomé-Açu se destacam dentre os demais, pois produtores locais conseguem desenvolver tecnologias e processos assemelhando-se às chamadas "ilhas de eficiência", ou seja, podem ser reproduzidos por outros produtores e sofrer algumas adaptações ao longo dos anos com as modificações do contexto socioeconômico e ambiental em que foram criados (Homma et al., 2014).

Essas adaptações relacionadas com as mudanças de mercado, preços dos produtos e fatores de produção, políticas públicas e outras no contexto socioeconômico e ambiental como pragas e doenças, plantios em áreas derrubadas de floresta densa ou vegetação secundária e outras variáveis afetam a dinâmica dos SAFs (Homma, 2016).

Elas podem servir de referência para a replicação para outros produtores, promovendo o nivelamento com as tecnologias e processos adaptados pelos próprios produtores. A imitação dessas tecnologias e processos poderia ser facilitada pelo fato de a linguagem ser a mesma entre a fonte e o receptor. Este mimetismo tem sido adotado por muitos pequenos produtores com SAFs mais simples.

Dessa forma o presente estudo tem por objetivo principal avaliar a dinâmica produtiva dos SAFs dos cooperados descendentes de japoneses da Cooperativa Agrícola Mista de Tomé-Açu (CAMTA) no período de 1974 até 2020. 


\section{Metodologia}

\section{1 Área de estudo}

O estudo foi realizado no Município de Tomé-Açu (Figura 1), Pará, localizado a uma latitude de $02^{\circ} 04^{\prime} 52^{\prime \prime}$ e

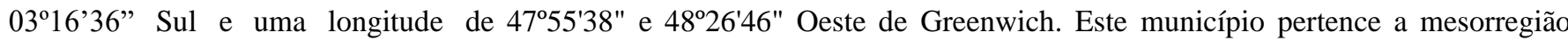
Nordeste Paraense e limita-se ao norte com os municípios de Acará e Concórdia do Pará, ao sul com Ipixuna do Pará, a leste com Aurora do Pará e a oeste com Tailândia e Acará. Está situado a 280 km de Belém por via rodoviária (PA-140) e 270 km com percurso pelos rios Acará e Guamá, utilizado até a década de 1960.

Figura 1. Localização do município de Tomé-Açu.
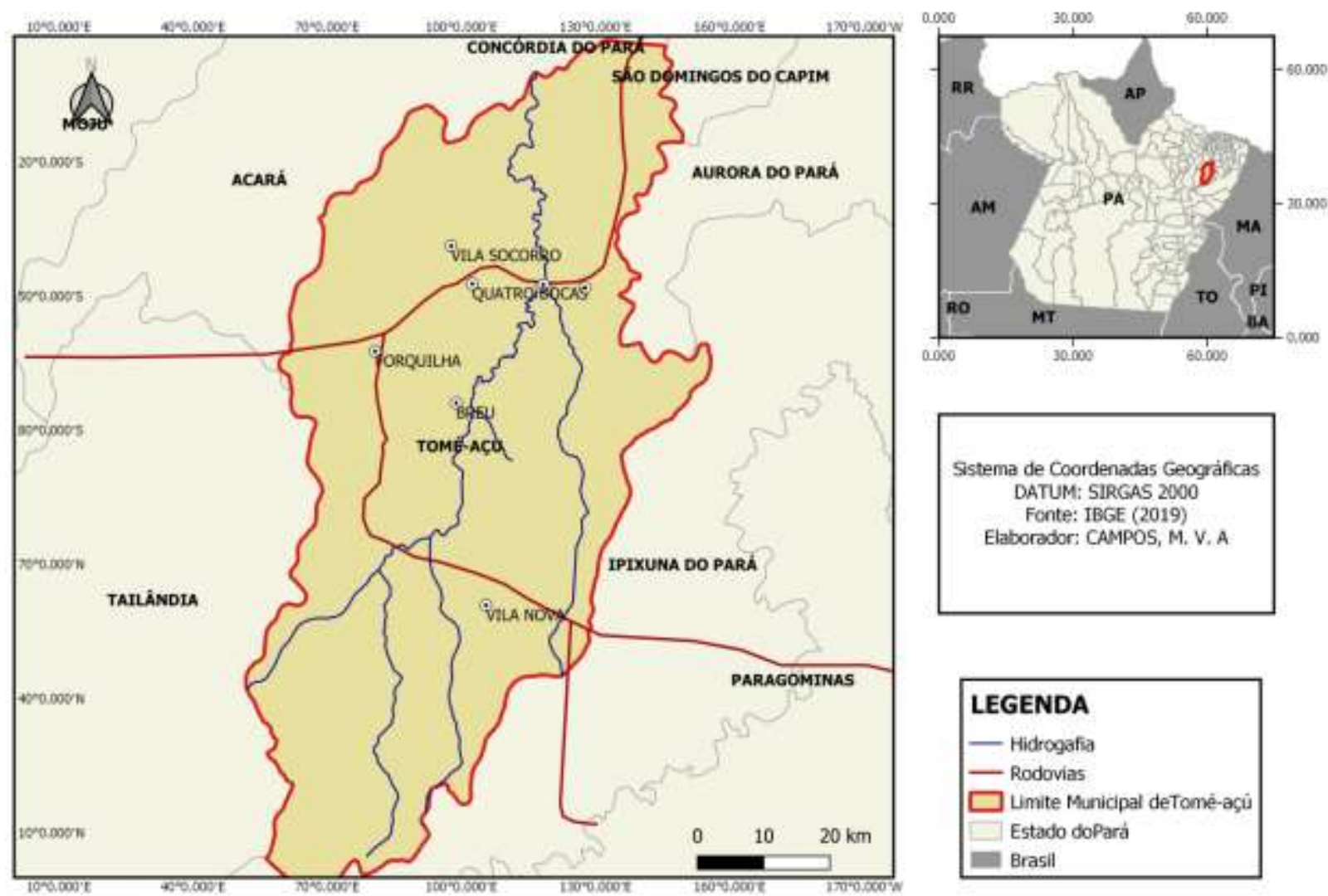

Fonte: Autores (2021).

Apresenta vegetação natural, caracterizada como floresta equatorial subperenifólia densa das terras baixas e densa aluvial, com vegetação secundária na forma de capoeiras, resultante da ação de atividades agrícolas, extrativistas e madeireiras e implantação de diferentes culturas agrícolas como a pimenteira-do-reino. Os ecossistemas naturais da mesorregião Nordeste Paraense, sofreram grandes alterações, provocadas pela forte pressão da ocupação humana na área, causando mudanças ambientais, devido ao desmatamento e prejudicando dessa forma a biodiversidade na região (IBGE, 2012).

A atividade predominante na economia do Município de Tomé-Açu é a agricultura, que constitui sua principal fonte de renda e que durante muitos anos foi representada pela plantação da pimenteira-do-reino. Com o declínio da cultura iniciaram-se outras atividades produtivas como fruticultura, pecuária, piscicultura e sobretudo pela extração madeireira (na maioria ilegal) em áreas de floresta. A despeito do desenvolvimento dos SAFs no Município de Tomé-Açu apresenta baixos níveis de renda per capita e dependência de transferências governamentais, indicando a drenagem de recursos para a cidade de Belém da população mais favorecida para moradia, estudos dos filhos e tratamento de saúde. O Municipio de Tomé-açu 
apresenta o índice Firjan de Desenvolvimento Municipal (IFDM) de 0,5362 em 2018, que o coloca na $64^{\circ}$ posição no Estado do Pará e sujeita a constante crises politicas na prefeitura local.

\subsection{Tipo de estudo e Coleta de Dados Secundários do IBGE (SIDRA e Censo Agropecuário 2017)}

Trata se de um estudo quantitativo, observacional, descritivo, retrospectivo e transversal. Os dados de produção e valor da produção foram obtidos através da plataforma SIDRA e do Censo Agropecuário 2017 (IBGE, 2019). As espécies analisadas no presente estudo são: açaizeiro (Euterpe oleracea), aceroleira (Malpighia punicifolia L.), cacaueiro (Theobroma cacao), cupuaçuzeiro (Theobroma grandiflorum), maracujazeiro (Passiflora edulis) e pimenteira-do-reino, que foram as plantas que mais se destacaram ao longo das décadas. Além destas plantas avaliou-se dados mais recentes da produção de pitaya [Hylocereus undatus (Haw) Briten \& Rose], que teve grande crescimento nos últimos anos. A partir desta seleção avaliou- se a quantidade produzida em nível estadual e nacional.

\subsection{Analise da contribuição de cada espécie para o valor da produção.}

Outro meio de coleta de dados foram os Relatórios A nuais da CAMTA, mais especificamente, avaliando o período de 1976 até o ano de 2020. A partir destes dados foi analisado o comportamento do percentual do valor de produção, ou seja, quanto, em porcentagem cada espécie contribuiu para a renda total da cooperativa em um determinado ano.

\subsection{Análise do Relatório de Atividade da CAMTA de 2020}

Primeiramente, foram selecionados 101 produtores nipo-paraenses associados da CAMTA, avaliando as espécies cultivadas por cada produtor. Estes constam nos Relatórios da CAMTA especificado a área, número de pés dos cultivos perenes e a produção para cada associado. A partir disso, observou-se a frequencia de presença de cada espécie, a partir do total de produtores avaliados. A escolha do ano de 2020 decorreu da análise dos atuais SAFs existentes, decorrentes do processo evolutivo que vem de décadas.

Posteriormente selecionou-se três culturas mais frequentes: açaízeiro, cacaueiro e cupuaçuzeiro. Para cada espécie selecionada foi elaborado um esquema geral com todas as associações e combinações de espécies a partir dos 101 produtores selecionados. Foram dispensados os produtores associados sem descendência japonesa e aqueles localizados em outros municípios.

\subsection{Analise de Dados}

Foi utilizado o software Microsoft Office Excel 2019 para a elaboração de tabelas e de gráficos de linha para melhor representarem o comportamento da porcentagem do valor de produção que cada espécie contribuiu ao decorrer do tempo.

\section{Resultados e Discussão}

\subsection{Produção no Cenário Nacional}

O Estado do Pará se destaca em relação à produção de açaí (extrativo, manejado e plantado), segundo os dados apresentados pela plataforma SIDRA, como maior produtor em todo território brasileiro, apresentando valor igual 1.539.612 toneladas obtidas no ano de 2020.

O cacaueiro é representativo no Estado do Pará, apresentando a maior produção de cacau do país com cerca de 144.682 toneladas, com cerca de 53,64\% da produção nacional, seguido do Estado da Bahia, a qual produziu cerca de 107.499 toneladas. Em relação quantidade produzida de maracujá, o Pará é o $10^{\circ}$ maior produtor do país e o maior da Região Norte com 15.105 toneladas. 
O Pará é segundo produtor de pimenta-do-reino no Brasil, apresenta cerca de 31,51\% da produção nacional com produção em 2020 igual 36.156 toneladas, tendo perdido a liderança para o Estado do Espirito Santo em 2017. Em relação a produção de cupuaçu, Censo Agropecuário 2017 registra equivocadamente o território paraense como $3^{\circ}$ maior produtor no Brasil, atrás do Amazonas e Bahia. Na verdade o Estado do Pará sempre foi o maior produtor nacional.

\subsection{Produção em Tomé-Açu}

O Município de Tomé-Açu se destaca no Estado do Pará como maior produtor de pimenta-do-reino e cupuaçu, apresentando valores iguais a 4.800 (2020) e 2.560 toneladas (2019), respectivamente.

A produção de açaí no município é pequena ficando na $21^{\mathrm{a}}$ posição, com apenas 12.320 toneladas (2020), sendo o açai beneficiado pela CAMTA na sua totalidade suprida de açaizeiros manejados do Município de Igarapé-Miri. Para acerola, maracujá e cacau, o município apresenta valores iguais a 720 (2019), 480 e 2.778 toneladas (2020), respectivamente, quantidade bastante reduzida em comparação com o Estado do Pará.

\subsection{Participação de cada espécie no Valor de Produção.}

Os dados tabulados são provenientes dos Relatórios Anuais da CAMTA, os quais correspondem a representatividade em valor de produção, em porcentagem, da pimenta-do-reino, maracujá, cupuaçu, acerola, açaí e o cacau no período de 1974 até 2020.

Em relação período de 1974 até 1987 (Tabela 1), neste espaço de tempo a pimenta-do-reino foi predominante na porcentagem de valor de produção, apresentando $89,6 \%$, porém há um decrescimento desta porcentagem com o tempo, ao mesmo tempo em que vai aumentando a diversificação das espécies a partir de 1976. Destaca-se neste período o inicio do crescimento das porcentagens de cacau e maracujá. A partir de 1981 podemos perceber o aumento na porcentagem de outras espécies cultivadas, isso se deve a diversificação de espécies usadas pelos cooperados, tais como mamoeiro hawai (Carica papaya), feijão (Phaseolus vulgaris) e milho (Zea mays).

Do período de 1988 até 2000 (Tabela 2) se destacou com acrescimo para o maracujá, cupuaçu e acerola, estes aumentos refletiram no decréscimo nas porcentagens de pimenta-do-reino. Na década de 1990, podemos destacar o crescimento da porcentagem no valor de produção nas culturas de açaizeiro, aceroleira e cupuaçuzeiro. Outro destaque nesta década é a queda nas porcentagens para o maracujá e cacau. A queda das porcentagens se dá também pelo aumento no valor da produção de espécies como abacaxizeiro (Ananas comosus), goiabeira (Psidium guajava), cajueiro (Anacardium occidentale) e taperebazeiro (Spondias mombin), provenientes de outros municipíos paraenses.

O período que vai de 1992 a 1999 apresentou crise no setor devido a queda dos preços internacionais, dessa forma, os produtores abandonaram os pimentais, dando oportunidade para pequenos produtores, os quais se adaptaram melhor a crise, pelo baixo uso de insumos modernos e uso da mão-de-obra familiar (Deser, 2008). Em 1993, o valor da produção comercializada de pimenta-do-reino atinge o menor valor de participação, com 12,17\%. A questtão ambiental estimulou o avanço da fruticultura e a diminuição do número de pimentais (Homma, 2004).

No período entre 2001 e 2020 (Tabela 3), o açaí, atingiu ao seu máximo de contribuição percentual igual a 48,7\%. O cacau também começou a apresentar crescimento durante esta década. A pimenta-do-reino apresenta a sua menor contribuição no percentual do valor de produção no ano de 2006 (11,3\%). Em 2011, pode-se perceber maior diversificação em relação a produtos como óleos das sementes [andiroba (Carapa guianensis), maracujá, etc.] e polpas. Outras frutas se destacaram nesse período como: caju, graviola, abacaxi e taperebá, equilibrando as porcentagens, e garantindo sua importância no valor da produção da CAMTA.

A partir de 2000, ocorre a alta de preços da pimenta-do-reino decorrente da desvalorização cambial de 14 de janeiro 
de 1999. Há diminuição nos financiamentos de novas áreas de pimentais no Estado do Pará, com recursos do Fundo Constitucional do Norte (FNO), que passaram a ter reflexos nos anos subsequentes, com a queda dos preços já a partir de 2002 (Homma, 2004).

Os pequenos produtores de pimenta-do-reino passam a incorporar fruteiras perenes, como o cacaueiro, o cupuaçuzeiro e o açaizeiro, bem como fruteiras anuais como o maracujazeiro, aproveitando as estacas das pimenteiras, antes ou após a morte delas.

A partir de 2011 foi marcado pelo êxodo rural de pequenos produtores causado pela expansão do dendezeiro, adquirindo suas propriedades e consequente redução na oferta de determinados produtos como cupuaçu, cacau, pimenta. Em resposta a isso a CAMTA intensificou o trabalho social com os pequenos e miniprodutores da região, realizando parcerias com a Hydro Mineradora cujo duto de $244 \mathrm{~km}$ que transporta a bauxita atravessa o Municipio de Tomé-Açu até atingir o Município de Barcarena onde é produzida a alumina e Wildlife Research Society (WRS), levando aos pequenos produtores qualificação no manejo de SAFs, gerenciamento de viveiros de mudas e gestão financeira (CAMTA, 2011). 
Research, Society and Development, v. 11, n. 1, e22811121000, 2022

(CC BY 4.0) | ISSN 2525-3409 | DOI: http://dx.doi.org/10.33448/rsd-v11i1.21000

Tabela 1. Percentagem na participação do valor da produção comercializada entre os cooperados da CAMTA, $1974-1987$.

\begin{tabular}{|c|c|c|c|c|c|c|c|c|c|c|c|c|c|c|}
\hline \multirow{2}{*}{ Produto } & \multicolumn{14}{|c|}{ Ano } \\
\hline & 1974 & 1975 & 1976 & 1977 & 1978 & 1979 & 1980 & 1981 & 1982 & 1983 & 1984 & 1985 & 1986 & 1987 \\
\hline Pimenta-do-reino & 99,17 & 96,17 & 89,58 & 78,98 & 77,21 & 76,84 & 73,04 & 70,41 & 49,9 & 46,71 & 66,59 & 75,84 & 79,14 & 78,42 \\
\hline Maracujá & 0,03 & 2,22 & 4,56 & 11,03 & 16,78 & 11,63 & 6,66 & 6,06 & 14,16 & 13,8 & 7,5 & 5,28 & 7,73 & 7,25 \\
\hline Cupuaçu & 0 & 0 & 0 & 0 & 0 & 0 & 0 & 0 & 0 & 0,12 & 0,26 & 0,31 & 0,45 & 0,96 \\
\hline Açaí & 0 & 0 & 0 & 0 & 0 & 0 & 0 & 0 & 0 & 0 & 0 & 0 & 0 & 0 \\
\hline Acerola & 0 & 0 & 0 & 0 & 0 & 0 & 0 & 0 & 0 & 0 & 0 & 0 & 0 & 0 \\
\hline Pitaya & 0 & 0 & 0 & 0 & 0 & 0 & 0 & 0 & 0 & 0 & 0 & 0 & 0 & 0 \\
\hline Outros* & 0,33 & 0,66 & 4,6 & 3,83 & 1,86 & 3,47 & 5,28 & 9,16 & 22,05 & 19,95 & 11 & 6,38 & 4,71 & 2,85 \\
\hline Total (\%) & 100,0 & 100,0 & 100,0 & 100,0 & 100,0 & 100,0 & 100,0 & 100,0 & 100,0 & 100,0 & 100,0 & 100,0 & 100,0 & 100,0 \\
\hline
\end{tabular}

*Outros: melão, mamão, pimentão, ovo, feijão, milho, borracha, limão, guaraná, abóbora, graviola, abacate, pepino.

Fonte: Dados básicos de Relatórios da CAMTA (1974-1987).

Tabela 2. Percentagem na participação do valor da produção comercializada entre os cooperados da CAMTA, 1988-2000.

\begin{tabular}{|c|c|c|c|c|c|c|c|c|c|c|c|c|c|}
\hline \multirow{2}{*}{ Produto } & \multicolumn{13}{|c|}{ Ano } \\
\hline & 1988 & 1989 & 1990 & 1991 & 1992 & 1993 & 1994 & 1995 & 1996 & 1997 & 1998 & 1999 & 2000 \\
\hline Pimenta-do-reino & 82,07 & 80,75 & 59,36 & 50,53 & 21,63 & 12,17 & 37,2 & 47,97 & 34,87 & 34,67 & 44,77 & 46,92 & 44,61 \\
\hline Maracujá & 7,2 & 7,27 & 23,13 & 35,7 & 32,72 & 49,94 & 23,8 & 7,98 & 20,06 & 13,43 & 8,34 & 7,71 & 12,03 \\
\hline Cupuaçu & 1,23 & 3 & 8,3 & 2,76 & 7,68 & 3,98 & 6,8 & 21,8 & 18,03 & 20,19 & 16,5 & 15,14 & 17,04 \\
\hline Acerola & 0 & 0 & 1,73 & 2,08 & 21,22 & 23,09 & 26,1 & 16,47 & 19,95 & 16,51 & 10,1 & 7,15 & 9,76 \\
\hline Cacau & 7,61 & 6,49 & 5,59 & 8,43 & 13,89 & 8,72 & 4,9 & 2,82 & 1,47 & 0 & 0,15 & 0,02 & 0 \\
\hline Açaí & 0 & 0 & 0 & 0 & 0 & 0 & 0 & 0 & 0 & 3 & 9,16 & 8,79 & 9,59 \\
\hline Pitaya & 0 & 0 & 0 & 0 & 0 & 0 & 0 & 0 & 0 & 0 & 0 & 0 & 0 \\
\hline Outros* & 1,89 & 2,49 & 1,89 & 0,5 & 2,86 & 2,1 & 1,2 & 2,96 & 5,62 & 12,2 & 10,98 & 14,27 & 6,97 \\
\hline Total (\%) & 100,0 & 100,0 & 100,0 & 100,0 & 100,0 & 100,0 & 100,0 & 100,0 & 100,0 & 100,0 & 100,0 & 100,0 & 100,0 \\
\hline
\end{tabular}

*Outros: melão, mamão, pimentão, ovo, feijão, milho, borracha, limão, guaraná, abóbora, graviola, abacate, pepino, baunilha, cardamono, dendê e taperebá.

Fonte: Dados básicos de Relatórios da CAMTA (1988-2000). 
Research, Society and Development, v. 11, n. 1, e22811121000, 2022

(CC BY 4.0) | ISSN 2525-3409 | DOI: http://dx.doi.org/10.33448/rsd-v11i1.21000

Tabela 3. Percentagem na participação do valor da produção comercializada entre os cooperados da CAMTA, 2001 a 2020.

\begin{tabular}{|c|c|c|c|c|c|c|c|c|c|c|c|c|c|c|c|c|c|c|}
\hline \multirow{2}{*}{ Produto } & \multicolumn{18}{|c|}{ Ano } \\
\hline & 2001 & 2002 & 2003 & 2004 & 2005 & 2006 & 2007 & 2008 & 2009 & 2010 & 2011 & 2012 & 2013 & 2015 & 2016 & 2018 & 2019 & 2020 \\
\hline Açaí & 8,19 & 8,71 & 16,2 & 20,7 & 27,99 & 48,73 & 46,26 & 20,76 & 24,12 & 27,91 & 20,8 & 21,51 & 42,46 & 41,08 & 16,94 & 15,34 & 18,54 & 16,55 \\
\hline Pimenta & 49,3 & 32,89 & 31,54 & 25,83 & 18,4 & 11,3 & 16,38 & 28,11 & 27,37 & 21,16 & 22,28 & 36,12 & 22,38 & 23,1 & 37,82 & 17,24 & 12,84 & 7,77 \\
\hline Cupuaçu & 9,31 & 10,45 & 9,48 & 9,98 & 7,78 & 6,45 & 6,76 & 9,28 & 8,58 & 10,87 & 7,42 & 5,56 & 5,16 & 4,36 & 6,06 & 8,03 & 7,18 & 7,82 \\
\hline Acerola & 4,69 & 5,7 & 6,26 & 6,96 & 8,1 & 6,01 & 5,38 & 5,79 & 6,53 & 7,43 & 6,17 & 5,15 & 4,6 & 3,8 & 5,92 & 8,66 & 8,24 & 7,19 \\
\hline Taperebá & 4,64 & 5,05 & 2,98 & 4,55 & 7,69 & 4,07 & 3,03 & 4,29 & 5,2 & 5,94 & 4,58 & 1,93 & 1,19 & 1,85 & 2,95 & 3,12 & 3,3 & 3,48 \\
\hline Goiaba & 3,56 & 4,15 & 4,56 & 5,05 & 5,85 & 4,8 & 3,9 & 4,27 & 4,72 & 5,54 & 4,81 & 4,41 & 3,82 & 2,97 & 4,29 & 5,94 & 5,6 & 4,89 \\
\hline Maracujá & 5,6 & 8,35 & 6,73 & 6,83 & 2 & 2,41 & 3 & 5,01 & 1,4 & 4,91 & 5,74 & 2,04 & 2,61 & 2,86 & 4,05 & 7 & 7,9 & 7,85 \\
\hline Graviola & 4,24 & 4,79 & 4,62 & 2,51 & 3,75 & 3,44 & 2,88 & 3,59 & 2,69 & 4,23 & 3,36 & 2,74 & 2,46 & 2,19 & 2,96 & 4,18 & 4,16 & 3,85 \\
\hline Abacaxi & 1,37 & 0,74 & 1,71 & 2,46 & 2,68 & 2,46 & 2,3 & 2,79 & 3,93 & 4,11 & 3,4 & 2,86 & 2,8 & 2,12 & 3,44 & 4,91 & 4,53 & 4,53 \\
\hline Cacau & 5,2 & 13,56 & 10,61 & 10,5 & 10,81 & 6,28 & 7,26 & 11,4 & 10,62 & 3,34 & 13,91 & 9,06 & 6,07 & 9,52 & 7,95 & 14,88 & 15,09 & 19,58 \\
\hline Caju & 2,56 & 2,8 & 2,81 & 2,54 & 2,92 & 2,08 & 1,53 & 1,83 & 2,39 & 1,7 & 1,99 & 2 & 1,99 & 1,71 & 2,48 & 3,08 & 3,25 & 3,03 \\
\hline Outros* & 1,34 & 2,81 & 2,5 & 2,09 & 2,03 & 1,97 & 1,32 & 2,88 & 2,45 & 2,86 & 5,54 & 6,62 & 4,46 & 4,44 & 5,14 & 7,62 & 9,37 & 13,46 \\
\hline
\end{tabular}

*Outros: carambola, manteiga de cupuaçu, caroço de cupuaçu, óleo de andiroba, polpa de cacau, manga, muruci, mudas, geleias e bacuri.

Fonte: Dados básicos de Relatórios da CAMTA. 


\subsection{Quantidade produzida pelas espécies}

Atualmente o principal produto industrializado pela CAMTA é o açaí, mas no começo era o maracujá, depois a acerola, cupuaçu. Outro mercado é o do sorbet, que está tendo boa aceitação no mercado de São Paulo. O principal mercado é o Estado do Pará, que representa praticamente 60\%, e o restante é dividido entre Maranhão e São Paulo, principalmente. Em termos de exportação, os maiores compradores são o Japão, a Argentina com a pimenta, a Alemanha, a Guiana Francesa e os Estados Unidos (Oppata, 2021).

Os dados de produção comercializada de açaí ao longo do tempo são apresentados na Figura 2. O açaí foi destaque de produção na década de 1990, apresentando crescimento no período que vai de 1996 até 2004. A partir deste paríodo pode-se perceber uma série de diversificações de produtos elaborados. Em 2004 são incluídos o açaí mix [misturado com guaraná (Paullinia cupana)] e o açaí popular. De 2008 até 2013 o açaí médio e especial teve participação significativa na quantidade produzida, em período posterior a 2013 limitou-se a produção de açaí comum e açaí mix. A quantidade comercializada de polpa de açaí sofreu retração de 2008 a 2011 e a queda de 2015 a 2020.

Figura 2. Quantidade comercializada de açaí de 1996-2020.

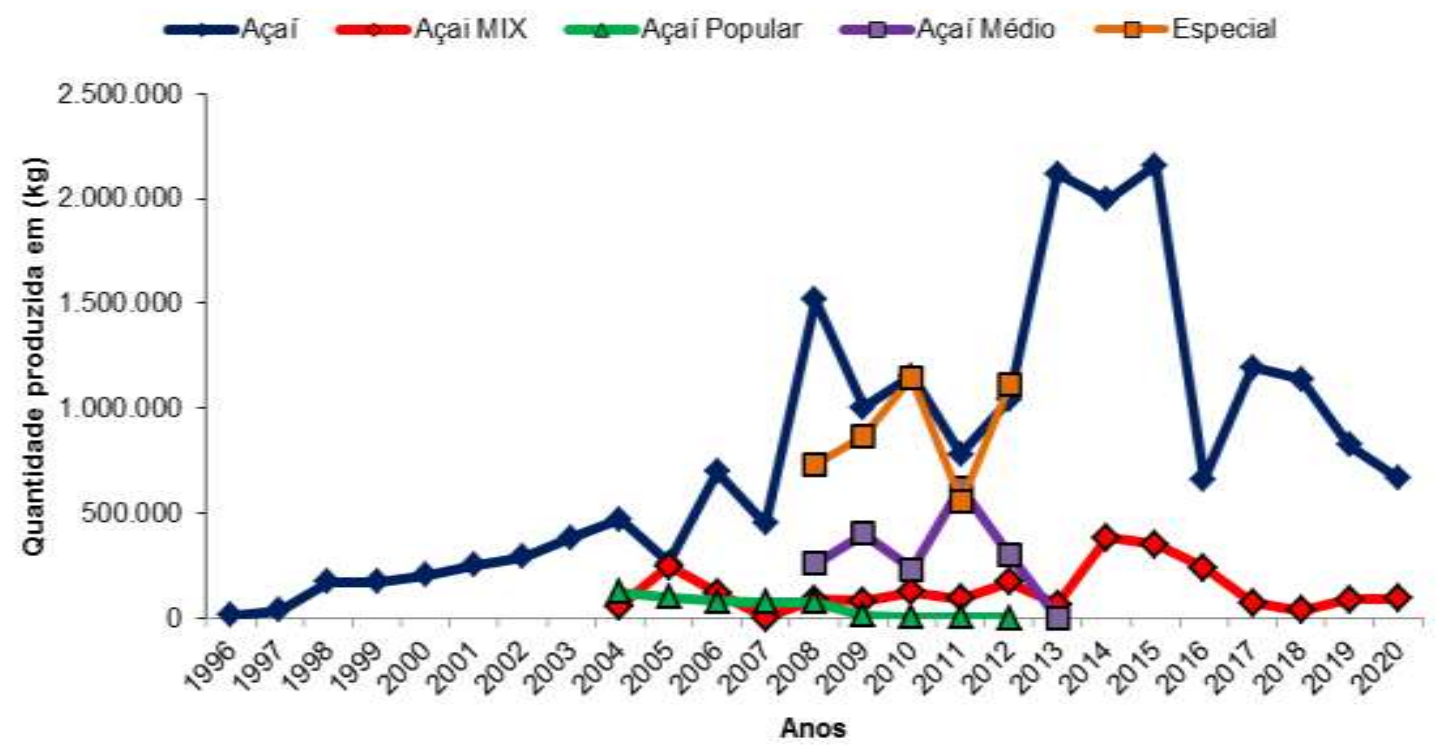

Fonte: Autores (2021).

Para os plantios em terra firme recomenda-se o uso da irrigação, sem o qual não é possível obter uma produtividade satisfatória e sujeita a veranicos como ocorreu em 2015 e 2016 com a morte das palmeiras. O lançamento das cultivares de açaizeiro BRS Pará, em 2004 e, da BRS Pai d'Égua, em 2019, pela Embrapa Amazônia Oriental, tiveram uma grande aceitação pelos produtores (Farias Neto, 2019).

A Figura 3 apresenta os dados de produção de cupuaçu de 1982 até 2020. Nos anos de 1982 até 1994, a produção oscilou apresentando maior valor em 1989 e quedas em 1991 e 1993. Em 1995 o crescimento acentuado se estendeu até o ano de 2017. O cupuaçuzeiro aumentou a produção devido a avanços tecnológicos em relação à genética da espécie. Um grande problema enfrentado pelos produtores é o combate a "vassoura-de-bruxa" (Moniliophthora perniciosa). Em 2002, a Embrapa Amazônia Oriental procedeu ao lançamento das cultivares Coari, Codajás, Manacapuru e Belém e, em março de 2012, lançou a cultivar BRS Carimbó, com mais tolerância à vassoura-de-bruxa e de maior produtividade (Alves et al., 2014). 
Em cada tonelada de fruto de cupuaçu, são obtidos $518 \mathrm{~kg}$ de casca $(51,8 \%), 378 \mathrm{~kg}$ de polpa $(37,8 \%)$ e $103 \mathrm{~kg}$ de amêndoas (10,3\%) que, depois de secas, rendem $56 \mathrm{~kg}$ (5,6\%) (Alves et al., 2014). Considerando um plantio de cupuaçuzeiros com 6 m x 6 m que totaliza 277 plantas/ha e uma produtividade média de $3.718 \mathrm{~kg} / \mathrm{ha}$ serão obtidos $208 \mathrm{~kg}$ de amêndoa seca e $1.405 \mathrm{~kg}$ de polpa. Em comparação com o cacaueiro, que chega a produzir $747 \mathrm{~kg} / \mathrm{ha}$ de amêndoa seca, ou seja, 3,6 vezes superior ao do cupuaçu.

Há necessidade do desenvolvimento de novas alternativas, como a implantação de indústria de bombons e cosméticos para aumentar a demanda. A oferta de amêndoas vai depender do aumento do consumo da polpa de cupuaçu.

Figura 3. Quantidade comercializada de cupuaçu de 1982-2020.

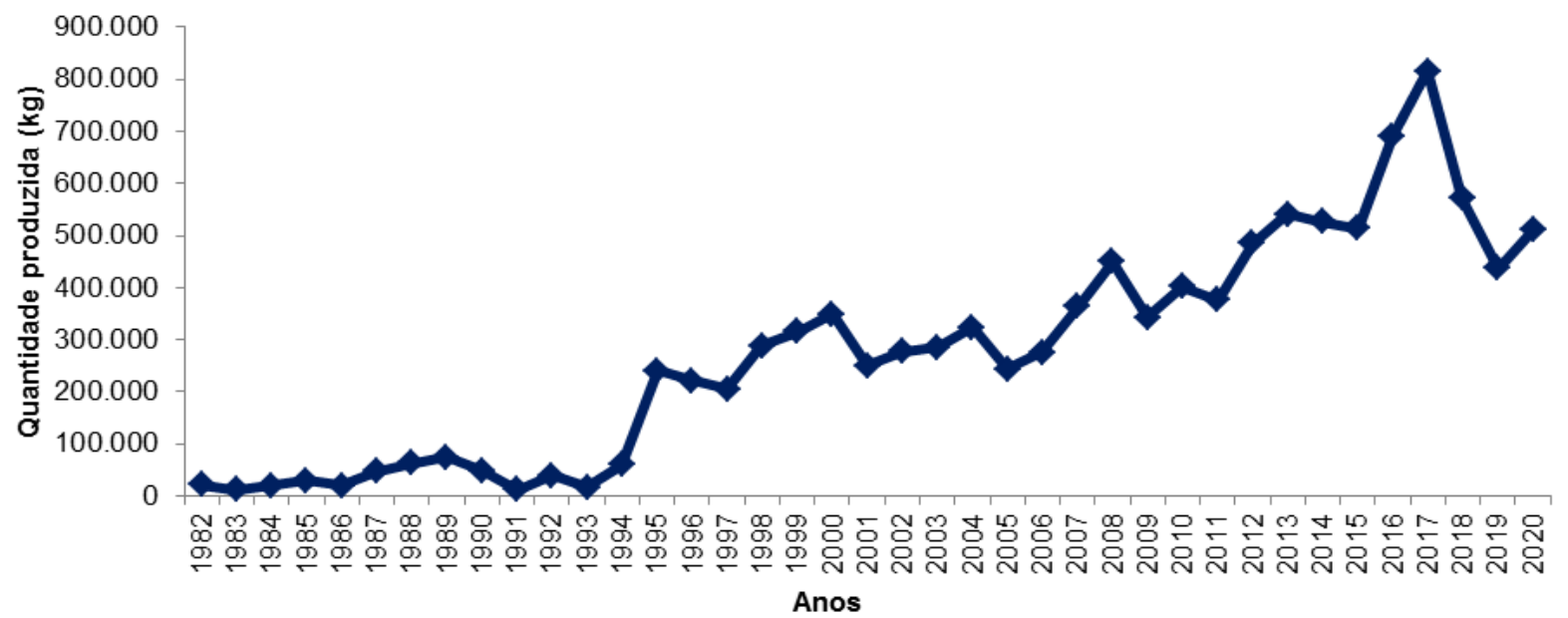

Fonte: Autores (2021).

Em relação a pimenta-do-reino (Figura 4), houve destaque em relação a sua produção nas décadas de 1970 e 1980 , sendo que o periodo posterior, caracerizou-se pelo decréscimo na quantidade produzida.

Nas décadas de 1950 e 1960, era predominante o monocultivo da pimenta- do-reino, isto acarretou em avanços tecnológicos para região, como a introdução do NPK nas culturas (Homma, 2016). Porém, no inicio da década de 1970, com a crise do petróleo o preço da pimenta do reino oscilou no mercado internacional e com o alastramento da fusariose os produtores japoneses e seus descendentes começaram a procurar alternativas agrícolas, uma delas foi a diversificação de culturas, dentre elas, destacam-se o maracujazeiro e o cacaueiro (Homma, 2016). 
Figura 4. Quantidade comercializada de pimenta-do reino (preta + branca) de 1976-2020.

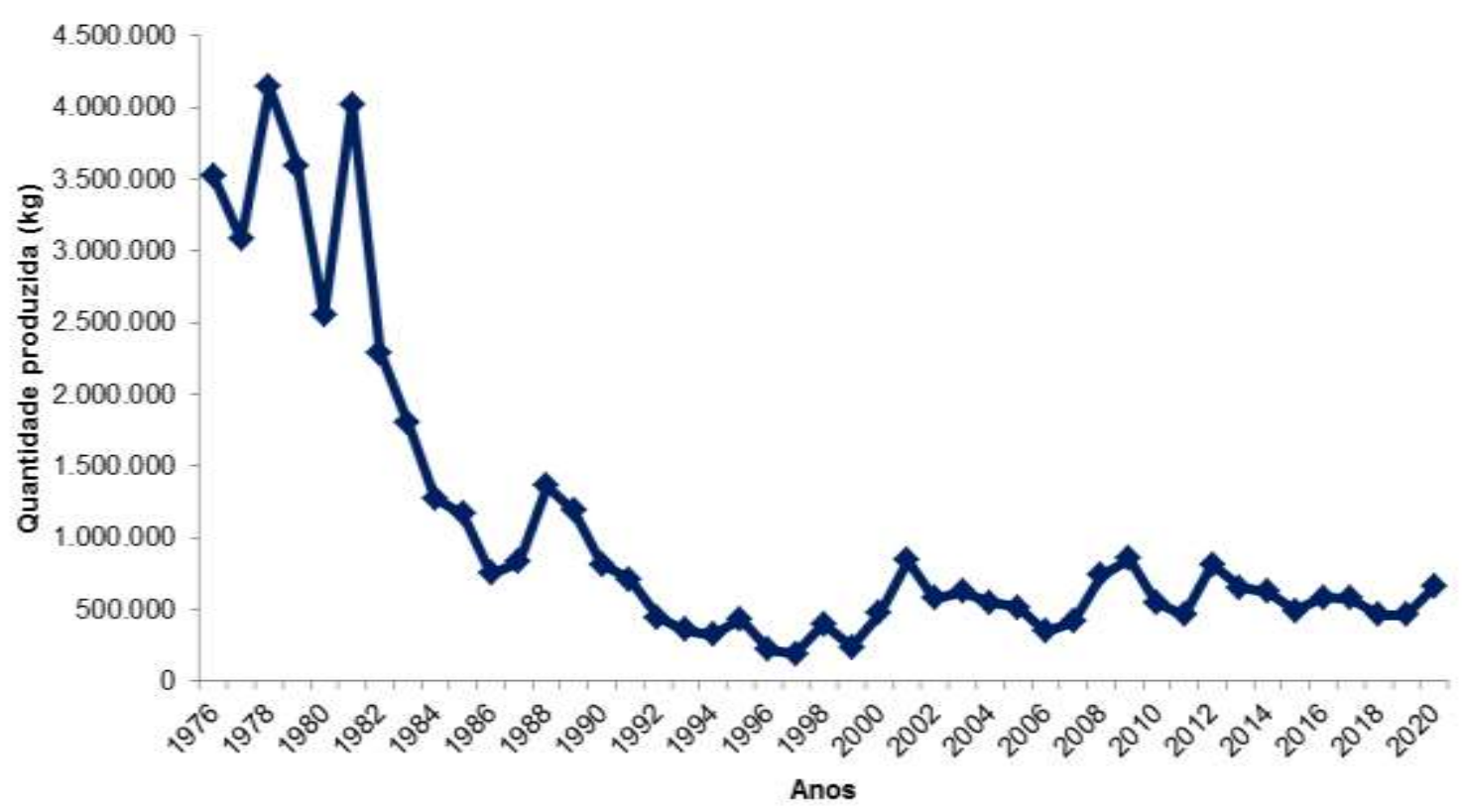

Fonte: Autores (2021).

O consumo do maracujá começou a crescer em meados da década de 1970 em nível mundial. O Brasil, que nem figurava entre os maiores produtores no começo dos anos 1970, chegou ao final da década como o maior exportador mundial. A cultura do maracujazeiro foi bem-vista, uma vez que as condições climáticas ajudam, mas logo causou uma superprodução e o consequente excesso de oferta nos mercados do Pará e São Paulo, levando a contínua queda nos preços. Dessa forma resolveu-se investir numa unidade industrial para produzir-se polpa de frutas e assim aproveitar melhor a fruta. A primeira agroindústria de polpa com 20 toneladas de capacidade de armazenamento foi erguida, em 1987, com a ajuda da JICA.

O Brasil é considerado o maior produtor de maracujá do mundo. No período de 1990 a 1995, o Estado do Pará foi o maior produtor de maracujá, perdendo a posição para a Bahia em 1996, quando passou a assistir ao gradativo decréscimo, ocupando, atualmente, a sétima posição. O Pará, em 1992, respondia por 47,86\% da produção nacional, enquanto, em 2014, passou para 2,47\%. Em 1996, o Estado da Bahia, com participação de 22,08\%, ultrapassou a produção paraense, que, naquele ano, representou $18,70 \%$ da produção brasileira. O processamento da polpa de maracujá foi à primeira agroindústria de polpa de fruta a ser instalada no Estado do Pará, sendo sua produção exportada em tambores refrigerados para outros estados e para o exterior.

O maracujá apresentou alta produção, principalmente nas decadas de 1970 e 1980, apresentando decréscimo acentuado de 1981 até 1986, seguido posteriormente por leves oscilações em sua quantidade produzida (Figura 5). A queda na produção ocorrreu devido a baixa dos preços. No ano de 1990 houve a tentativa de retornar a alta produção através do financiamento do FNO, junto ao Banpará. O alto custo com materias-primas e a baixa eficiência dos produtores foram também fatores que prejudicaram a produtividade do maracujá. Realizava-se o sistema sequencial da pimenta-do-reino plantando a cultura do maracujazeiro na cova da pimenteira morta ao lado da estaca, sendo que ambas espécies são beneficiadas pelas mudas de árvores tanto pela sombra quanto pela ação quebra-vento (Yamada, 2009).

A produção de maracujá no Estado do Pará está muito relacionada com a expansão do cultivo da pimenta-do-reino. Enquanto as pimenteiras estão crescendo, é possível aproveitar os estacões, estendendo-se um fio de arame liso e reduzindo dessa maneira o custo de implantação do pimental. Com o fim do ciclo de vida do maracujazeiro, a pimenteira está próxima do 
início de sua primeira safra.

Figura 5. Quantidade comercializada de maracujá de 1977-2020.

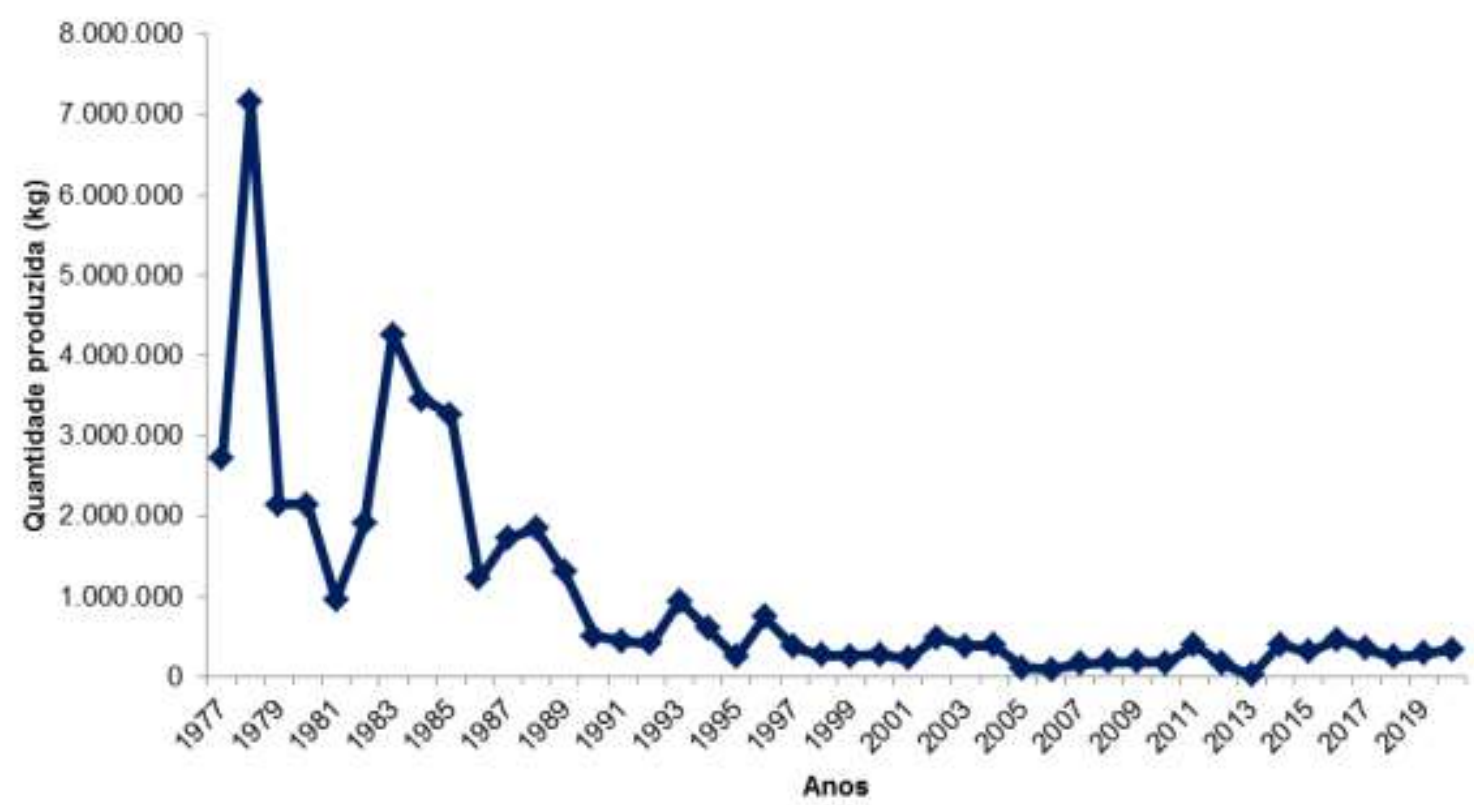

Fonte: Autores (2021).

Com a imigração japonesa para a região, em 1929, o cacaueiro foi considerado como planta base para a sustentação econômica dos imigrantes (Homma, 2016). A falta de pesquisa e de maiores conhecimentos sobre essa cultura em áreas de terra firme redundou em fracasso, superado mais tarde com o sucesso da pimenta-do-reino.

O cacaueiro seria lembrado novamente na segunda metade da década de 1960, como alternativa para ocupar as antigas áreas de pimentais dizimados pelo Fusarium e para servir de suporte econômico para os grandes projetos de colonização que foram desencadeados a partir da década de 1970, na Transamazônica paraense e em Rondônia.

Com a entrada da vassoura-de-bruxa nos cacauais da Bahia, em 1989, ganharam importância os cacaueiros plantados no Estado do Pará de 208 mil hectares dos quais 150 mil em produção. A expansão dos cacaueiros nos estados do Pará e em Rondônia foi decorrente do Procacau, iniciado em 1976, sendo a segunda cultura perene com maior área plantada. A ocorrência da vassoura-de-bruxa reduziu a produção baiana pela metade e o País tornou-se um importador desse produto. Apesar da presença dessa doença nos cacauais da Amazônia, essa convivência já vem de longa data, dificultando o seu controle se não forem desenvolvidas variedades mais resistentes.

Na safra 1964/65 a produção mundial aumentou $25 \%$ e os preços caíram para US\$250,00/t. No período que vai de 1971 até 1977 os preços internacionais da amêndoa do cacau subiu de US\$ 500,00/t para US\$ 5.700,00/t aumentando dez vezes.

O cacaueiro apresentou destaque na sua produção nas décadas de 1970 e 1980, apresentando grandes pícos de produção e também grandes quedas. No fim da década de 1970 para o inicio da década de 1980, há um acentuado crescimento, isto ocorre porque nos anos de 1975 e 1976, os agricultores de Tomé-Açu realizaram plantio de um milhão de pés de cacaueiros como alternativas ao monocultiva de pimenta (Figura 6). Após 1977 o aumento na oferta mundial de cacau fizeram o preço cair para US\$1.600,00/t até por volta de 2000, com aumento de produção. Em 24/12/1999 ocorreu o primeiro golpe de Estado deste a independência da Costa do Marfim e repetida em 2002, fizeram disparar os preços internacionais do cacau para US\$2.700.00/t. 
Os anos 2000 foi um período de alto investimento e aumento na produção e vendas. Esta subida de preços se acentua a partir de 2006 decorrente do déficit na produção e das tensões políticas na Costa do Marfim alcançando US\$ 4,200,00/t em março de 2011. Dessa forma durante a década 2001 até 2010, os preços subiraram de US\$ 925,00/t para US\$1.600,00/t.

No ano de 2010, a CAMTA participou do International Cocoa Award, em Paris, onde o cacau tipo C-27 foi selecionado como um dos melhores do Planeta.

Figura 6. Quantidade comercializada de cacau de 1977-2020.

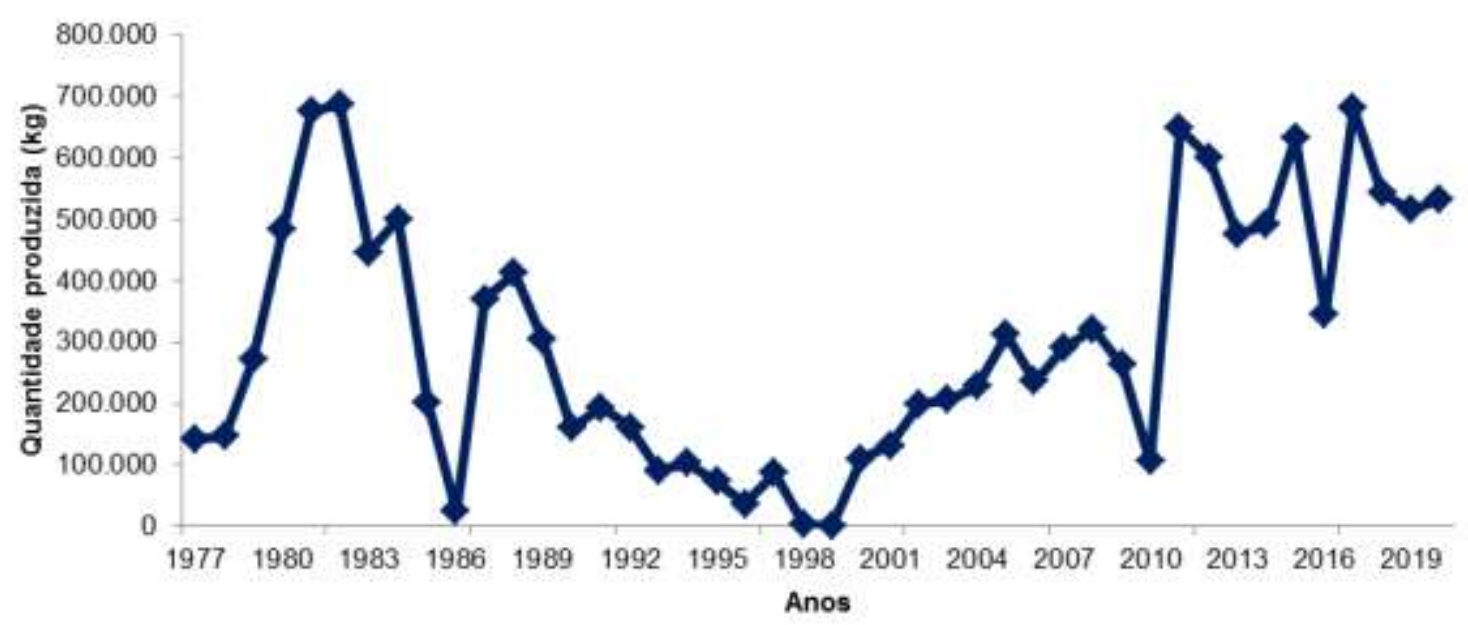

Fonte: Autores (2021).

O primeiro produto paraense a receber o registro de Indicação Geográfica foi o cacau de Tomé-Açu. A conquista foi obtida oficialmente no dia 29/01/2019 com a publicação da concessão na Revista da Propriedade Industrial No 2.508, do Instituto Nacional da Propriedade Industrial (INPI). A Associação Cultural e Fomento de Tomé Açu (ACTA) é a detentora do registro, responsável por manter um conselho regulador que deve preservar, divulgar, proteger os produtos registrados, sua qualidade e procedência.

O grande diferencial do cacau de Tomé-Açu, exportado para a Meiji, que controla 1/4 do mercado de chocolates no Japão, se deve pela forma como é cultivado, através do Sistema Agroflorestal de Tomé-Açu (SAFTA), um modelo exclusivo de agricultura desenvolvido pela comunidade nipo-paraense. Aproveitando a realização dos Jogos Olímpicos de Tokio 2020, mas realizado em julho a agosto de 2021, o chocolate da Meiji, recebeu o selo comemorativo, associando ao evento (Cacau, 2021).

O cacaueiro plantado pelos descendentes de japoneses em Tomé-Açu e em outros municípios onde se cultiva esta cultura tende a ser desenvolvido em combinação com outras plantas, seja frutífera, madeireiras ou apenas sombreadoras. Os produtores na Transamazônica, também, vêm investindo cada vez mais na produção de amêndoas especiais com maior cuidado no plantio, manejo, colheita, fermentação e armazenamento, tendo recebido prêmios quanto ao blend e na fermentação acelerada.

A acerola a partir de 1991 apresentou grande evolução na sua quantidade produzida apresentando picos de produção nos períodos de 1991 a 1996 e 2015 até 2018 (Figura 7). A produção e comercialização do fruto foi baixa devido ao aumento das exigências em relação a qualidade do produto, principalmente, aos teores de Brix e vitamina $\mathrm{C}$, além disso o aumento da produção em outras regiões do Brasil resultou na queda dos preços, desse modo, desestimulando os produtores. Em 1996 houve melhoria na qualidade e beneficiamento dos produtos, estimulando no crescimento em vendas e na produtividade. 
Figura 7. Quantidade comercializada de polpa de acerola de 1987-2020

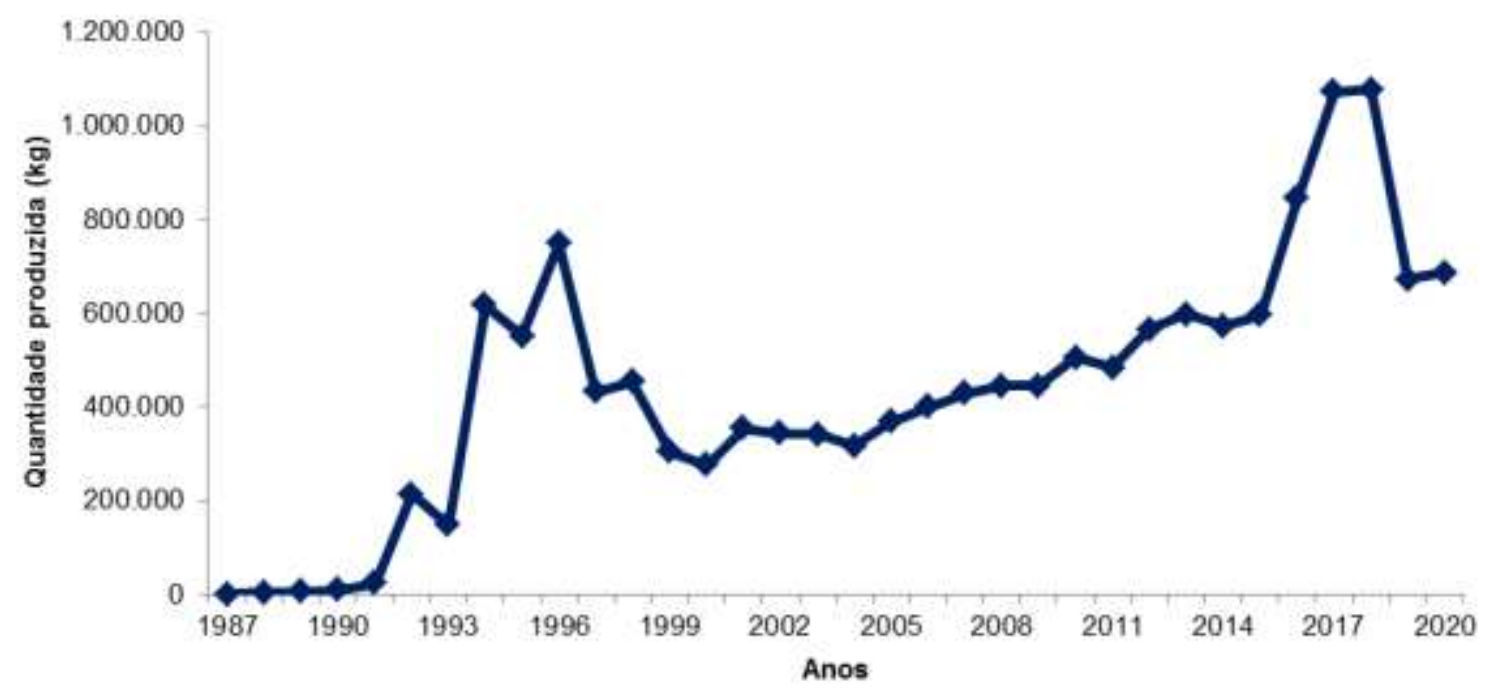

Fonte: Autores (2021).

Por seus trabalhos na difusão do mamoeiro hawai, em 1984, os imigrantes japoneses Noburu Oya e Hidehiko Fujiwara receberam o Prêmio Kiyoshi Yamamoto, bem como Teruo Shimomaebara, de Castanhal, em 1993, pelos seus trabalhos com acerola. Devido a concorrência dos plantios do Nordeste a produção acerola está voltada mais para o mercado local.

O Estado do Pará é o $4^{\circ}$ maior produtor nacional de pitaya do País (com 10,74\% da produção nacional), tendo o município de Tomé-Açu como principal polo produtivo (92,70 toneladas) cuja produção dos cooperados aumentou de 2014 a 2018 (Froés Júnior et al. 2019).

Por ser um fruto de alta perecibilidade e sujeita a traumatismos que modificam o paladar, exigem cuidados especiais no transporte e comercialização. A partir de 2018 a polpa de pitaya começou a ser comercializada sem semente influenciando na quantidade produzida e comercializada dos frutos com semente (Figura 8).

A produção da cultura está atualmente concentrada na região Sudeste, com cerca de 812,64 toneladas produzidas em 2017, contribuindo com 54,42\% da produção nacional. A região Sul com 502,08 toneladas, responde por 33,62\% da produção e a Norte, com 157,01 toneladas, por 10,51\% da produção nacional, são as três regiões mais representativas nesse cultivo.

Figura 8. Quantidade comercializada de polpa de pitaya de 2014-2020.

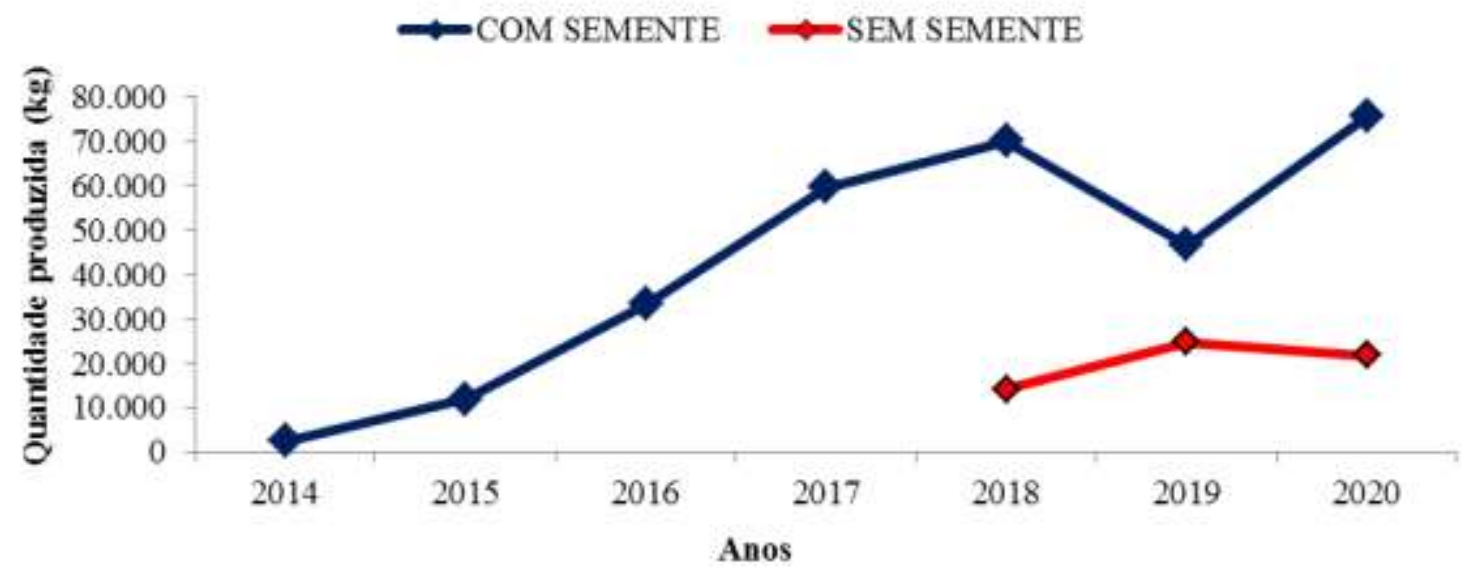

Fonte: Autores (2021). 


\subsection{Cenário Produtivo da CAMTA em 2020.}

A Figura 9 apresenta as espécies cultivadas e a frequencia em que cada espécie apresenta em relação aos 101 produtores nipo-paraenses analisados no relatório da CAMTA de 2020. Dentre as espécies mais frequentes destacam-se: o açaízeiro (72\%), cupuaçuzeiro (65\%), cacaueiro (61\% especial e 57\% em amêndoa).

Figura 9. Frequência das espécies cultivadas pelos 101 produtores nipo-paraenses.

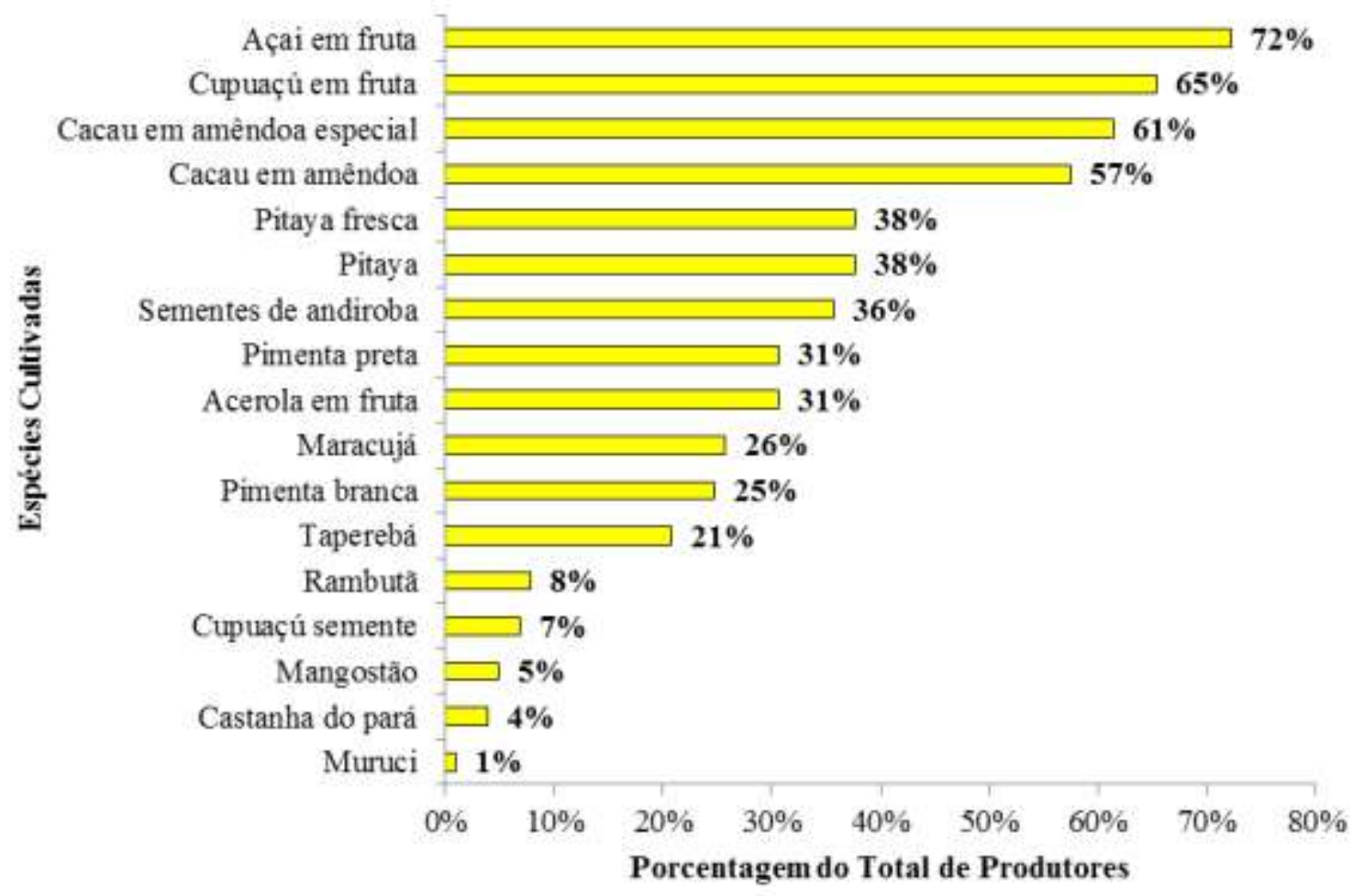

Fonte: Autores (2021).

\subsection{Principais culturas e combinações utilizadas em 2020}

Os resultados obtidos através do Relatório 2020 da CAMTA apresentaram três combinações mais frequentes: açaí/cupuaçu (54,5\%), açaí/cacau $(51,5 \%)$ e açaí/cacau/cupuaçu $(38,6 \%)$. Estas três predominam na questão de produção em $48,5 \%$ das 101 propriedades analisadas.

Na Figura 10, foram computados 15 propriedades onde o açaizeiro é a cultura principal, sendo 14 SAFs e um monocultivo. A principal consorciação realizada com o açaizeiro é o cacaueiro (13 associações), a combinação entre açaizeiro, cacaueiro e cupuaçuzeiro foi realizada em oito propiedades cujo principal cultivo é o açaizeiro. 
Figura 10. Sistemas agroflorestais identificados para 101 produtores nipo-paraenses onde o açaizeiro é a cultura principal.

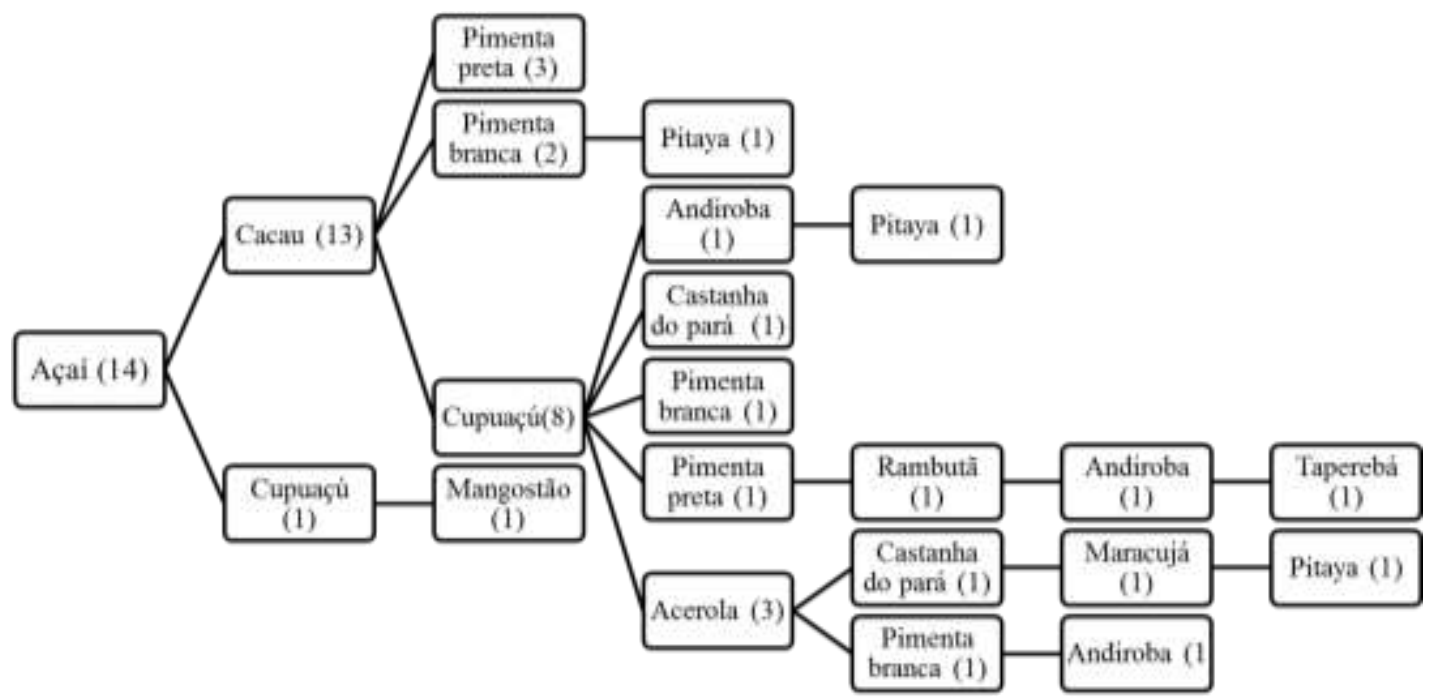

Fonte: Autores (2021).

Em relação à Figura 11, a qual destaca as combinações onde o cupuaçuzeiro foi a principal cultura, ao todo 24 cooperados apresentam como a principal cultura, sendo 20 sistemas agroflorestais e quatro monocultivos. A principal cultura associada ao cupuaçuzeiro é a do açaizeiro, totalizando 19 associações. A combinação cupuaçuzeiro/açaizeiro/cacaueiro apresenta participação 14 sistemas, e a combinação cupuaçuzeiro/açaizeiro/aceroleira totalizaram cinco associações.

O esquema da Figura 12 mostra as combinações em que o cacaueiro foi a principal cultura, sendo 10 cooperados utilizando esta espécie, sete para SAFs e três para monocultivo. A principal espécie associada com o cacaueiro foi o açaizeiro com quatro associações.

A castanheira do pará está integrado em muitos SAFs em Tomé-Açu. O Brasil passou a importar castanha da Bolívia e do Peru a partir de 1997, chegando a mais de 5,6 milhões de dólares e mais de 474 toneladas de amêndoas em 2017. No Estado do Pará temos experiência de plantios desenvolvidos pelos produtores nos municípios de Tomé-Açu e Acará e plantios experimentais da Embrapa Amazônia Oriental em Belém, Capitão Poço e Medicilândia. Há cerca de 3.435 castanheiras plantadas somente entre os cooperados da CAMTA. O Estado do Amazonas tem um plantio de 3 mil hectares com 300 mil castanheiras enxertadas, plantadas no início da década de 1980, em plena produção. As castanheiras deveriam ser utilizadas para recompor o passivo ambiental da Áreas de Reserva Legal e de Preservação Permanente, dando sentido econômico nessa recuperação. 
Figura 11. Sistemas agroflorestais identificados para 101 produtores nipo-paraenses onde o cupuaçuzeiro é a cultura principal.

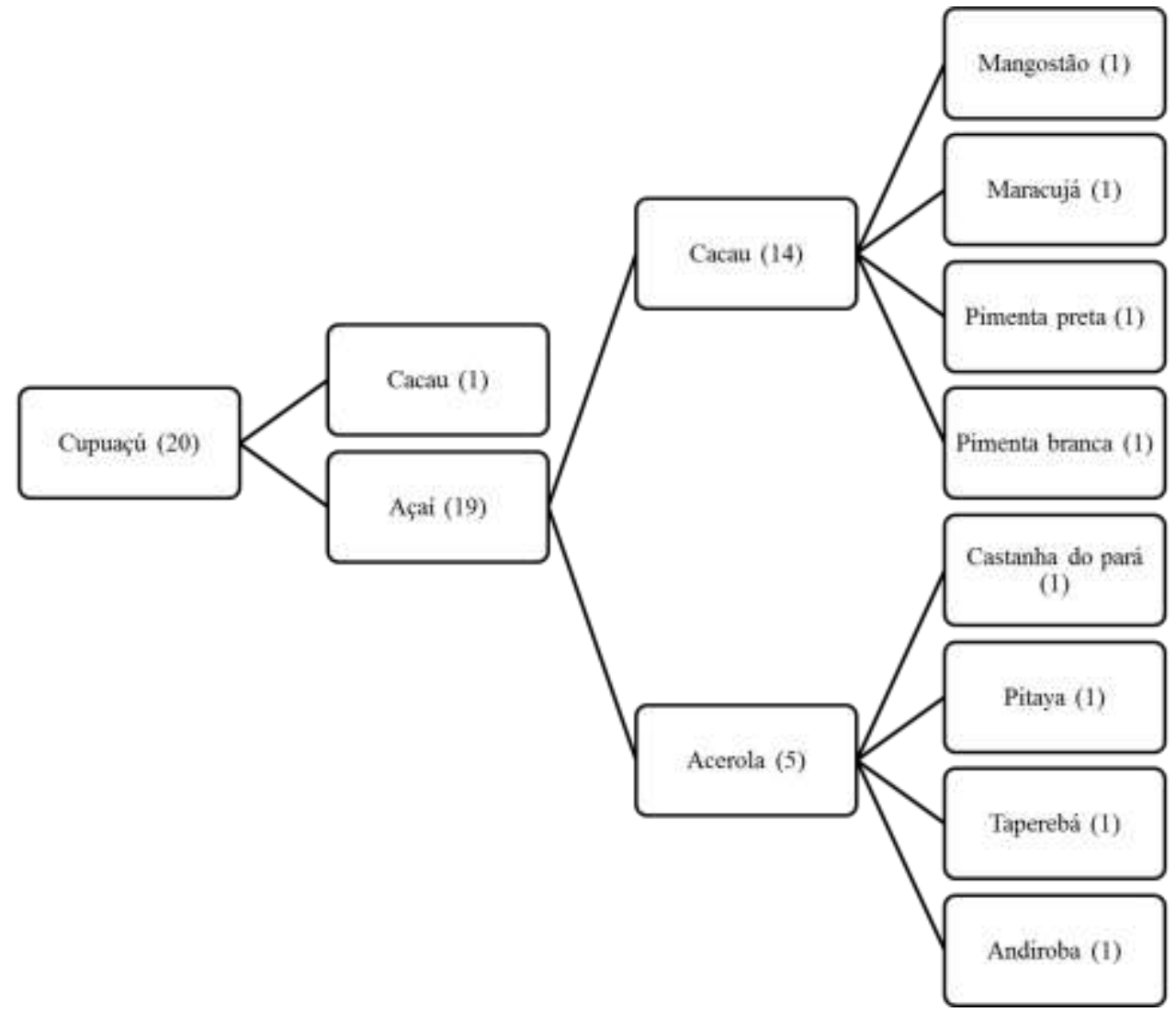

Fonte: Autores (2021).

Figura 12. Sistemas agroflorestais identificados para 101 produtores nipo-paraenses onde o cacau é a cultura principal.

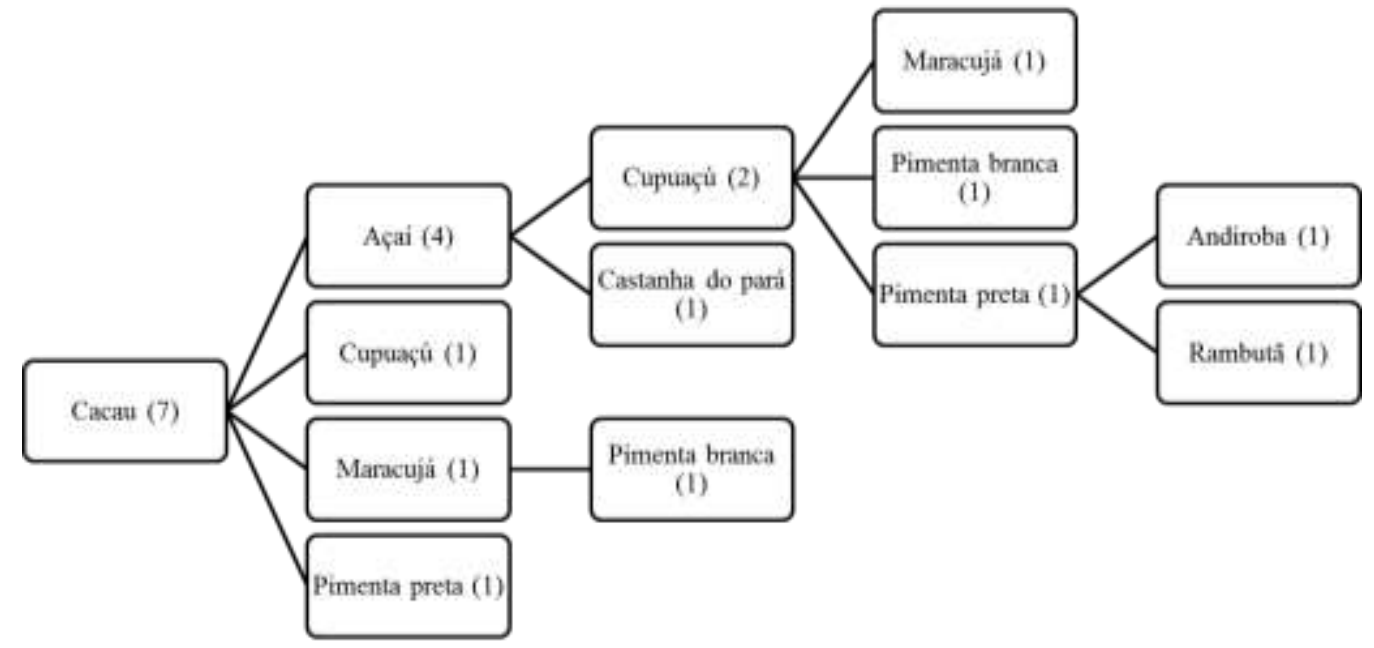

Fonte: Autores (2021).

\section{Considerações Finais}

Os agricultores nipo-paraense mostram uma característica ímpar se comparado com a de outras áreas do Estado do Pará em termos da adoção de SAFs. As atividades produtivas giram em torno de cacaueiro, cupuaçuzeiro, pimenteira-do-reino, açaizeiro, maracujazeiro, espécies florestais, culturas anuais, pequenos animais, entre os principais

As produções desenvolvidas pelos colonos nipo-paraenses, representam, em constante resposta, as modificações do 
mercado, contornar o surgimento de pragas e doenças, limitações legais e dos erros e acertos das suas iniciativas. Estas experiências se constituem em resultados de observações e tentativas de erros e acertos que precisam ser traduzidos para o universo de pequenos produtores locais.

A despeito da apologia dos SAFs, os resultados apontam que uma atividade-eixo, com forte presença no mercado, constitui na razão da viabilidade econômica, do que o objetivo da combinação de culturas perenes. Sendo o inicio da década de 1970 marcado pela diversificação das plantas utilizadas, os quais eram voltados para o plantio de pimenteira-do-reino, porém com a crise econômica neste período e o desenvolvimento da fusariose, houve incentivo para plantio de espécies como cacaueiro e maracujazeiro. A procura pela diversificação de plantas devido à crise da pimenteira do reino, trouxeram os SAFs, o qual foi sendo desenvolvido concomitantemente aos inúmeros "experimentos" locais, que geraram amplitude de possibilidades e combinações com diferentes espécies.

No contexto econômico, os SAFs utilizados pelos cooperados nipo-paraenses em Tomé-Açu não devem ser analisados em um corte seccional. As condições atuais decorrem de um processo evolutivo desde a década de 1920. O desenvolvimento de determinadas culturas, o crescimento do mercado para produtos específicos, o aparecimento de pragas e doenças, a busca de novas alternativas, a atitude positiva quanto ao risco e, sobretudo a organização dos produtores, constituem possíveis relações de causa-efeito que culminaram no atual processo produtivo. O eixo indutor dessas mudanças está relacionadas com o sucesso dos problemas decorrentes, posteriormente, com a cultura da pimenta-do-reino. O desenvolvimento dos SAFs não decorreu de uma política implícita, mas das perspectivas de mercados e da estratégia de utilização das terras. Muitos SAFs existentes não apresentam nenhuma importância econômica ou já foram importantes no passado ou são incompatíveis em termos de utilização de mão-de-obra.

Pode-se observar que as mudanças nos SAFs estão estritamente vinculadas aos preços da pimenta-do-reino, como uma das causas. Os baixos preços da pimenta-do-reino e a disseminação do Fusarium levaram os produtores a procurarem novas alternativas econômicas. A crise nessas novas alternativas faz com que os produtores estejam sempre atentos a novas mudanças. Dessa forma, no futuro, outras atividades completamente distintas poderão ocupar o espaço das atuais culturas (baunilha, uxizeiro, bacurizeiro, etc). As atividades dos colonos nipo-paraenses envolvem mais de trinta produtos em diversas combinações, onde os produtores se especializam para determinados processos produtivos.

Não existe um SAF, mas um conjunto de SAFs que no decorrer do tempo, com as transformações do mercado, dos preços dos produtos, pragas e doenças, legislação trabalhista e ambiental, entre outros, fazem com que os produtores promovam constantes mutações espaciais e temporais. Os SAFs não podem ser considerados como opção permanente, mas adequando-se para cada categoria de produtores, levam tempo para a sua implantação e exige dedicação na sua formação.

Como alternativa aos impactos sociais e econômicos no período de 2010 até 2018, a CAMTA desenvolveu programas de capacitação do pequeno produtor, com parceria com empresas privadas. Essas capacitações estavam relacionadas a gestão de viveiros, insumos e mercadorias geradas, para que este pequeno produtor esteja apto a contornar os problemas socioeconômicos e ambientais no período.

As combinações de açaizeiro/cupuaçuzeiro (54,5\%), açaizeiro/ cacaueiro (51,5\%) e açaizeiro/cacaueiro/cupuaçuzeiro $(38,6 \%)$ foram as mais frequentes encontradas entre os cooperados nipo-paraenses da CAMTA. Estas três predominam na questão da produção em 48,5\% em relação as 101 propriedades analisadas.

\section{Agradecimentos}

A Cooperativa Agrícola Mista de Tomé-Açu na pessoa do seu presidente Alberto Kei`Iti Oppata e Mitinori Konagano pelo fornecimento dos Relatórios e informações, a FAPESPA, Banco da Amazônia e Embrapa Amazônia Oriental no apoio 
para o desenvolvimento da pesquisa de campo em Tomé-Açu.

\section{Referências}

Almeida, A. S. (2019). Percepção de serviços ecossistêmicos por agricultores familiares na Amazônia Oriental: subsídios para a restauração florestal. 62 f. Dissertação (Mestrado em Ciências Ambientais) - Instituto de Geociências, Universidade Federal do Pará, Museu Paraense Emílio Goeldi, Empresa Brasileira de Pesquisa Agropecuária.

Alves, R. M., Filgueiras, G. C., \& Homma, A. K. O. (2014). Aspectos socioeconômicos do cupuaçuzeiro na Amazônia: do extrativismo a domesticação. In: Santana, A. C. (ed.). Mercado, cadeias produtivas e desenvolvimento rural na Amazônia. UFRA, 197-223.

Barros, A. V. L. de, Homma, A. K. O., Takamatsu, J. A., Takamatsu, T., \& Konagano M. (2009). Evolução e percepção dos sistemas agroflorestais desenvolvidos pelos agricultores nipo-brasileiros do município de Tomé-açu, estado do pará. Amazônia: Ci. \& Desenv., 5 (9), $07-37$.

Bolfe, E. L., \& Batistella , M. (2011). Análise florística e estrutural de sistemas silviagrícolas em Tomé-Açu, Pará. Pesq. agropec. bras., Brasília, 46 (10), $1139-147$.

Camta. (2010). Relatório da Diretoria: Exercício 2010. Tomé-açu.

Camta. (2011). Relatório da Diretoria: Exercício 2011. Tomé-açu.

Carneiro-Junior, J. F. C., Lima, J. M. de, Silva, A. L. P. da, \& Nascimento, M. N. C. F. (2015). Análise de mercado da pimenta-do-reino de no período de 1990 a 2015. Tecnologia \& Ciência Agropecuária, , 11 (6), 139-145.

Deser. (2008). Departamento de estudos sócio-econômicos. Secretaria de Agricultura Familiar. Curitiba, novembro.

Farias Neto, J. T. de. (2019). BRS Pai d'Égua cultivar de açaí para terra firme com suplementação hídrica. Belém: Embrapa Amazônia Oriental 7p. (Comunicado Técnico, 317).

Fróes Júnior, P. S. M., Cardoso, N. R. P., Rebello, F. K., Homma, A. K. O., \& Lopes, M. L. B. (2019). Aspectos da Produção, Comercialização e Desenvolvimento da Cultura da Pitaya no Estado do Pará. Enciclopédia Biosfera. Centro Científico Conhecer: Goiânia, 16 (29), $264-279$.

Homma, A. K. O. (2004). Civilização da pimenta-do-reino na Amazônia. Amazônia: meio ambiente e desenvolvimento agrícola. Brasília, DF: EMBRAPASPI; Belém, PA: EMBRAPA-CPATU, 1998. 61-91.

Homma, A. K. O. (2006) Organização da produção e comercialização de produtos agropecuários: o caso da colônia agrícola nipo-brasileira de Tomé-Açu, Pará In: Vilcahuamán, L.J.M., Ribaski, J., Machado, A.M.B. Sistemas agroflorestais e desenvolvimento com proteção ambiental: perspectivas, análise e tendências. Colombo: Embrapa Florestas. 51-77.

Homma, A. K. O. (2007). Imigração japonesa na Amazônia: sua contribuição para o desenvolvimento agrícola. EMBRAPA Amazônia Oriental.

Homma, A. K. O. (2006) A imigração japonesa na Amazônia: sua contribuição ao desenvolvimento agrícola. (2a ed.), Embrapa, 255 p. Comemoração dos 120 anos da assinatura do Tratado de Amizade, Comércio e Navegação Japão-Brasil, em 5 de novembro de 1895 , em Paris e dos 85 anos da imigração japonesa no Estado do Amazonas, em 20 de junho de 1931).

Homma, A. K. O. (2004). Dinâmica dos sistemas agroflorestais: o caso da Colônia Agrícola de Tomé- Açu, Pará. Revista do IESAM, 2 (1/2), 57- 65.

Homma, A. K. O., Menezes, A. J. E. A. de, \& Barros, A. V. L. de. (2014). Dinâmica dos sistemas agroflorestais: o caso da colônia agrícola de Tomé-Açu, Pará. In: Homma, A. K. O.(Ed). Extrativismo vegetal na Amazônia: história, ecologia, economia e domesticação. Brasília: Embrapa. $425-436$.

Homma, A. K. O. (2016). A imigração japonesa na Amazônia: sua contribuição ao desenvolvimento agrícola. (2a ed.), Embrapa.

IBGE (2019). Instituto Brasileiro de Geografia e Estatística. Resultados do Censo Agropecuário 2017. https://censos.ibge.gov.br/agro/2019.

IBGE. (2012). Manual técnico da vegetação brasileira. IBGE

Kato, O. R., Shimizu, M. K., Borges, A. C. M. R., Azevedo C. M. B. C., Oliveira, J. S. R. O., S. S.; \& Vasconcelos, S. S., Sá, T. D. A. (2012). Desenvolvimento da produção de frutas em sistemas agroflorestais no estado do Pará. XXII CONGRESSO BRASILEIRO DE FRUTICULTURA. Bento Gonçalves, 22 a 26 de outubro.

Nascimento, D. R. do, Alves, L. N., \& Souza, M. L. (2019). Implantação de sistemas agroflorestais para a recuperação de áreas de preservação permanente em propriedades familiares rurais da região da Transamazônica, Pará. Agricultura familiar: pesquisa, formação e desenvolvimento, Belém, 13 (2), 103-120.

Oppata, A. K. (2021). A formação da CAMTA e da SAFTA. In: 13º BUNKYO RURAL: Sistema Agroflorestal - SAFTA em Tomé-Açu, Sociedade Brasileira de Cultura Japonesa e Assistência Social, São Paulo, SP. 51-66.

Rodrigues, T. E. et al (2001). Zoneamento agroecológico do município de Tomé- Açu, Estado do Pará. Belém: Embrapa Amazônia Oriental. 81p. Embrapa Amazônia Oriental Documentos n. 118.

Tafner Junior, A. W. \& Silva, F. C. (2014). Colonização nipônica na Amazônia: A saga dos imigrantes japoneses no estado do Pará. R. Pós Ci. Soc. São Luis, 11 (22), jul-dez.

Yamada, M. (2009). Uma breve história de desenvolvimento agroflorestal nikkei na Amazônia: o caso da colônia de Tomé-Açu, PA. In. Porro, R. (Edit. Tec.) Alternativa agroflorestal na Amazônia em transformação. Brasília, DF: Embrapa Informação Tecnológica, 691-704. 